\title{
COMPARISON OF THREe FDTD MODELING TECHNIQUES FOR COAXIAL FEED
}

\author{
Amir Hajiaboli* and Milica Popović \\ McGill University, Electrical and Computer Engineering Department \\ Montréal, Canada H3A 2A7 \\ amir.hajiaboli@mail.mcgill.ca
}

\section{Introduction}

This paper addresses the difficulties reported in numerical modeling of coaxial feed probes [1]. A range of finite-difference time-domain (FDTD) modeling techniques (e. g., gap, magnetic frill and transmission line modeling) was successfully applied for specific applications. We here challenge the same problem for the case of electromagnetically coupled patch antenna (EMCP). This structure has intricate resonance behavior and operates based on two-mode excitation. These two modes have close values of resonant frequency [3] and can be revealed only with precise probe modeling. The following modeling techniques for the probe feed have been implemented and compared with the measurement results: electric gap modeling, sub-cell modeling of inner conductor and very fine discretization of coaxial probe. The results are discussed in the light of advantages and downsides of each technique and the associated computational parameters to obtain a reliable solution.

\section{Antenna Structure}

Cross-sectional view of the antenna is depicted in Fig. 1.

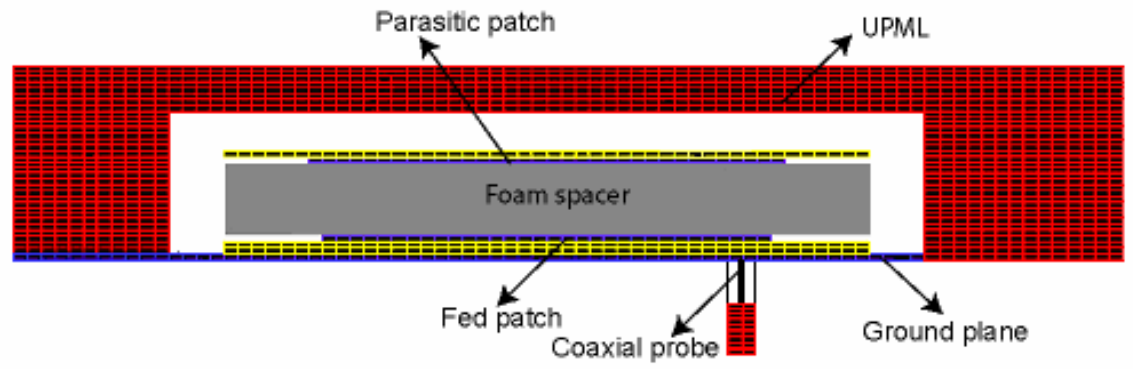

Figure 1. Cross-sectional view of the antenna structure.

The antenna is comprised of two stacked patches, separated by a foam layer $\left(\varepsilon_{\mathrm{r} \text {-foam }}=1\right)$. Both patches are etched on a $0.81-\mathrm{mm}$ substrate $\left(\varepsilon_{\text {r-substrate }}=3.38\right.$, $\left.\tan \delta_{\text {substrate }}=0.0027\right)$. Another substrate layer is added to the fed-patch, where the two substrate layers are glued to result in the total thickness of $1.74 \mathrm{~mm}$, with assumed $0.12-\mathrm{mm}$ glue (electrically modeled as air) layer, modeled with Maloney-Smith method for thin dielectric sheet [4]. The dimensions of interest 
are as follows: fed-patch $64 \mathrm{~mm} \times 68 \mathrm{~mm}$, upper patch $72 \mathrm{~mm} \times 72 \mathrm{~mm}$, finite ground plane $100 \mathrm{~mm} \times 100 \mathrm{~mm}$. The radius of the outer conductor of the coaxial probe is $5 \mathrm{~mm}$ and of the inner conductor is $1 \mathrm{~mm}$. For all the simulations reported in this paper, the FDTD problem resulted in a total of $90 \times 90 \times 90$ cells.

\section{Numerical Modeling Techniques of the Coaxial Probe}

We here present three different modeling techniques of the coaxial probe:

Electric gap modeling. Here, the antenna is excited with a resistive voltage source at the location of the feed. The details of FDTD update equations are given in [4]. This modeling technique is characterized by simplicity in implementation, and for the applications reported in the literature it has shown good agreement with measured data [5].

Sub-cell modeling of inner conductor. Here, the inner conductor of the coaxial probe is modeled using the sub-cell modeling for the thin wire [6]. As mentioned before, the air gap beneath the fed patch is modeled with the thin sheet, and this calls for separate treatment of the updating equations for the thin wire at the junction with the thin air gap. Eq.1 shows the updating of the $y$-component of the magnetic field $H_{\mathrm{y}}$. Here, we use the contour path modeling technique [4] of thin wire but we consider the discontinuity of the electric field in the $z$-direction.

$\left.H_{y}\right|_{i, j, k} ^{n+\frac{1}{2}}=\left.H_{y}\right|_{i, j, k} ^{n-\frac{1}{2}}+\frac{\Delta t}{\Delta z \mu_{0}}\left(\left.E_{x}\right|_{i, j, k-\frac{1}{2}} ^{n}-\left.E_{x}\right|_{i, j, k+\frac{1}{2}} ^{n}\right)+\frac{\Delta t}{\mu_{0} \frac{\Delta x}{2} \Delta z \ln \left(\frac{\Delta x}{r_{0}}\right)}\left(\left.E_{z}\right|_{i-\frac{1}{2}, j, k} ^{n}(\Delta z-\Delta g)-\left.E_{z, i n}\right|_{i+\frac{1}{2}, j, k} ^{n}(\Delta g)\right)$

where $r_{0}$ is the radius of the inner conductor of the coaxial probe and $\Delta g$ is the thickness of air gap beneath the lower patch, and the remaining standard FDTDrelated notation can be found in [4].

Fine discretization of the inner conductor. Finally, the inner conductor is modeled using the fine discretization of FDTD cells around the coaxial probe, earlier investigated in the context of its effect on calculation of input impedance of a monopole antenna [1]. In this technique, we implement a graded mesh for the region around the feed point in a precise manner to avoid unwanted reflections from the cell junctions.

\section{Results and Conclusion}

Figs. 2(a) and 2(b) graph the results for real and imaginary part of input impedance obtained using the three techniques above, along with the measurement results for comparison. In addition, Table I summarizes the computational parameters for each technique. The following can be observed from the presented results:

1. The electric gap modeling technique, although simple and straightforward in implementation, results in a $50-\mathrm{MHz}$ shift between the measured and simulated resonance frequency. Further, we note the discrepancy between the model and the measured data around $1.25 \mathrm{GHz}$. Table I suggests that this method calls for a large number of iterations as it converges to the final solution. 


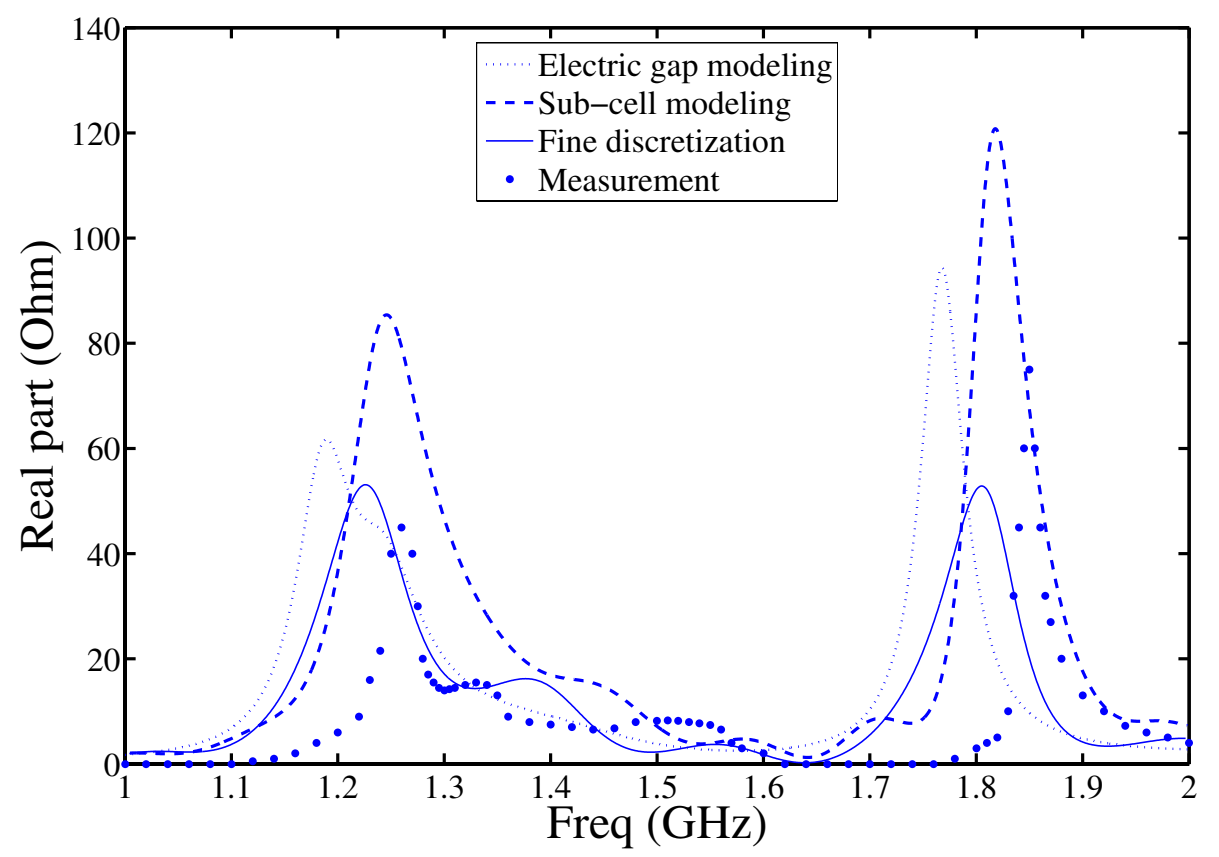

(a)

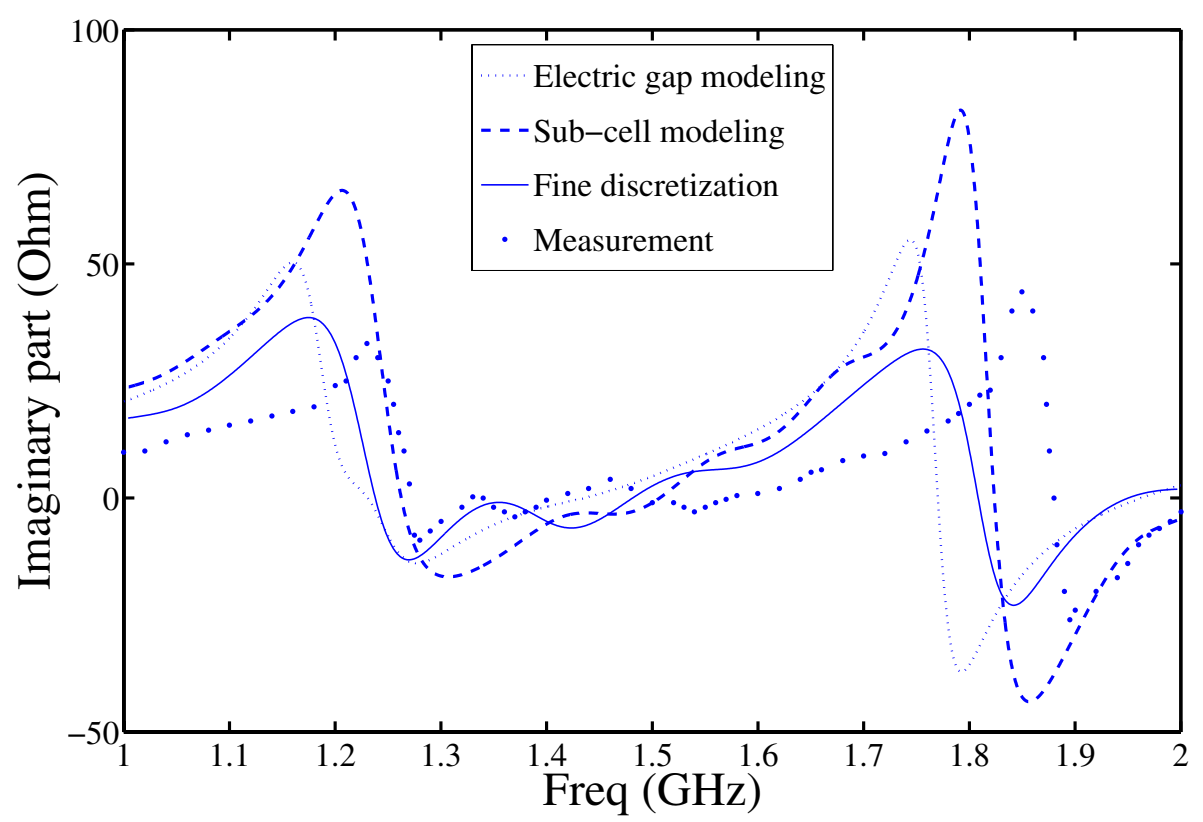

(b)

Figure 2. (a) Real and (b) imaginary part of the input impedance, calculated with three different techniques for the model of coaxial probe shown of the antenna structure in Fig. 1. The measurement data are included as a benchmark for comparison of the three modeling methods. 
2. The sub-cell modeling of the inner conductor of the coaxial probe demonstrates an improved agreement with the measured data with respect to the previously mentioned technique, both in resonant frequency and in the data at $1.25 \mathrm{GHz}$. Table I demonstrates advantageously smaller number of iterations needed by this technique for convergence to the final result.

3. The fine discretization of the inner conductor results in superior matching of input impedance around $1.25 \mathrm{GHz}$ with respect to the two methods above, however, Table I shows it is computationally intensive in comparison with the sub-cell modeling technique.

TABLE I.

COMPARISON OF COMPUTATIONAL PARAMETERS FOR THE TECHNIQUES USED TO OBTAIN RESULTS OF FIG.2.

\begin{tabular}{|c|c|c|c|}
\hline $\begin{array}{c}\text { Technique for } \\
\text { modeling the } \\
\text { coaxial probe feed }\end{array}$ & $\begin{array}{c}\text { Minimum cell dimension } \\
\text { in three coordinates: } \\
\Delta x, \Delta y, \Delta z(\mathrm{~mm})\end{array}$ & $\begin{array}{c}\text { Time step } \\
\Delta t(\mathrm{ps})\end{array}$ & $\begin{array}{c}\text { Number of iterations } \\
\text { needed for convergence } \\
\text { to the final solution }\end{array}$ \\
\hline Electric gap & $2,2,0.56$ & 1.6661 & 17000 \\
\hline Sub-cell & $1.25,1.25,0.56$ & 1.5138 & 6000 \\
\hline Fine discretization & $0.25,0.25,0.56$ & 0.5395 & 12000 \\
\hline
\end{tabular}

\section{Acknowledgement}

This work was funded by Natural Science and Engineering Research Council (NSERC) of Canada. The authors are grateful for their support.

\section{References}

[1] T. W. Hertel, G. S. Smith, "On the convergence of common FDTD feed models for antennas, "IEEE Transactions on Antennas and Propagation, Vol. 51, No. 8, August 2003, pp. 1771-1779

[2] G. Kumar, K. P. Ray, Broadband Microstrip Antennas, Artech House, Inc, 2003.

[3] J-F. Zucher, Broadband Patch Antenna, Artech House, In., 1995.

[4] A. Taflove, Computational Electrodynamics: The Finite Difference TimeDomain Method, Artech House, Inc., 1995.

[5] E. Nishiyama, M. Aikawa, "FDTD Analysis of stacked microwtrip antenna with high gain", Progress in Electromagnetics Research Symposium (PIERS), pp. 29-43, 2001.

[6] M. A. Jensen, Y. Rahmat-Samii, "Performance analysis of antennas for handheld transceivers using FDTD", IEEE Transactions on Antennas and Propagation, Vol. 42, no. 8, August 1994, pp. 1106-1113 